\title{
Celebrando 20 anos do regime remuneratório experimental em Cuidados de Saúde Primários: uma reflexão pessoal sobre um percurso único
}

Jaime Correia de Sousa*

$\square$ m 2 de novembro de 2019 celebram-se vinte anos desde o início da atividade das primeiras unidades de saúde em Regime Remuneratório Experimental (RRE).

Celebrar os 20 anos das primeiras USF não é apenas festejar o aniversário da data de nascimento do RRE; é, sobretudo, comemorar um percurso coletivo de entrega e de compromisso entre os profissionais das equipas e para com os cidadãos inscritos e utilizadores dessas unidades de saúde.

Escrever sobre o percurso das primeiras unidades em RRE através destes vinte anos da sua existência é também narrar uma fase decisiva da história dos Cuidados de Saúde Primários (CSP) em Portugal. Quer queiramos quer não, as primeiras unidades em RRE estarão sempre intimamente ligadas à criação e desenvolvimento das Unidades de Saúde Familiar (USF) e da história da reforma dos CSP, que se iniciou oficialmente em 2005.

Embora haja ainda quem considere que as USF apenas nasceram em 2005 e persista numa atitude quase negacionista em relação a tudo o que se passou entre finais de 1999 e o arranque formal das USF em 2005, a realidade é bem diferente. A história das USF em Portugal começou bem antes de 2005, com os primeiros projetos Alfa em $1996^{1}$ e com o RRE em 1999. ${ }^{2}$ O que é certo é que as candidaturas apresentadas pelas primeiras USF, que iniciaram funções em novembro de 1999 e as que abriram nos primeiros meses de 2000, já levavam clara-

*Médico de Família. USF Horizonte, Matosinhos.

Professor Associado Convidado. Escola de Medicina, Universidade do Minho. mente expressa nos documentos de candidatura a sigla USF - Unidade de Saúde Familiar. É por isso legítimo que, ao celebrar os 20 anos do RRE estejamos na realidade a celebrar o início das primeiras USF.

Este texto, mais do que uma crónica ou um artigo académico, procura ser um excerto muito pessoal de impressões, opiniões e aspirações de alguém que viveu intensamente todo este percurso que se iniciou, como referi, muito antes da data oficial de arranque dos primeiros RRE.

Há muitos anos que, assaltados pela desinquietação constante e pelo desejo de praticar uma medicina familiar mais próxima dos modelos teorizados nos constantes debates em que participavam praticamente desde a criação da carreira, muitos médicos de família ambicionavam conseguir trabalhar num modelo organizacional e retributivo que correspondesse aos seus anseios. Os modelos teóricos estavam lá, nos numerosos documentos produzidos e que foram entregues aos sucessivos ministros da saúde, muito em particular no famoso Livro Azul da Associação Portuguesa dos Médicos de Clínica Geral (APMCG), lançado em 1991. ${ }^{3}$

Mas o modelo USF não se limitou a ser proposto através da referida obra. Antecipando estas propostas de transformação da Medicina Geral e Familiar (MGF) foi sendo desenvolvida, ao longo dos anos, uma profusa reflexão colectiva, alguma produção académica e a publicação de textos e de trabalhos de investigação que permitiram consubstanciar uma certa linha de pensamento. Este conjunto de reflexões foi determinante para gerar consensos alargados sobre o que era necessário fazer para mudar os CSP em Portugal e para pre- 
parar a fase seguinte, a da concretização dos projetos de inovação. Assim, foram publicados vários textos, escritos bem antes de 1998, altura em que se publicou o primeiro diploma legal do RRE. António Rodrigues e José Luís Biscaia tinham já publicado em 1991, na Revista Portuguesa de Clínica Geral (RPCG), um texto intitulado Pensar uma "Unidade de Medicina de Família", onde o conceito USF era já desenvolvido. ${ }^{4} \mathrm{Em} 1994$ foi publicado um artigo de reflexão, na ACTA MÉDICA PORTUGUESA, onde se sugeria a criação de unidades de medicina familiar muito semelhantes ao que veio a ser definido para as USF e no qual se desenvolveram propostas da sua estrutura e funções. ${ }^{5} \mathrm{Em}$ 1998, a APMCG publicou a Declaração da Madeira, uma espécie de segundo fôlego do Livro Azul, ${ }^{6}$ recomendando a criação de condições para que o regime remuneratório experimental recentemente aprovado em Conselho de Ministros constituísse uma alternativa credível ao regime remuneratório vigente e que efetivamente premiasse quem mais e com maior qualidade trabalha.

Quando a legislação desenvolvida pela equipa de colaboradores da Ministra da Saúde Maria de Belém, coordenada por Constantino Sakellarides, foi publicada em maio de 1998 veio encontrar muitos médicos de família cheios de expectativas e prontos para a ação. Assim, foram vários os grupos de médicos de família que começaram a tentar organizar-se para lançarem as primeiras candidaturas a RRE.

É importante que se perceba que, até à redação dos primeiros textos pela equipa que preparou as primeiras candidaturas, nada ou quase nada existia escrito para apoiar a construção de uma USF, como regras organizacionais, modelos de articulação, planos de atividades ou outros textos que hoje existem de forma profusa. Tudo teve de ser escrito de raiz, com base no que existia na literatura produzida e balizado pelos diplomas legais. Foi uma tarefa de criação coletiva em que se conseguiu juntar alguns documentos existentes em publicações públicas e alguns dos textos que tínhamos escrito anteriormente ou nos quais tínhamos colaborado para desenhar as regras iniciais de organização e articulação de uma equipa e do seu compromisso para com os cidadãos.

Esta aposta na iniciativa e auto-organização dos profissionais, na promoção da qualidade e na contratualização não foi uma tarefa fácil. Foi preciso vencer mui- tas resistências quer internas quer externas. Nem todos os elementos das equipas que iniciaram funções em novembro de 1999 partilhavam a mesma visão e concebiam o modelo organizacional da mesma forma. Por isso, o trabalho inicial de discussão conceptual e sobre formas de estar e praticar foi fundamental para podermos concretizar os nossos anseios. É difícil mudar hábitos de muitos anos e conceber uma nova forma de estar; defrontámo-nos com alguma resistência. As principais motivações para aderir a este novo modelo de trabalho foram a possibilidade da escolha dos profissionais entre si, a possibilidade de decidirmos sobre a nossa organização de forma autónoma, a possibilidade de melhorar a qualidade assistencial e o facto de a maior e melhor trabalho corresponder uma melhor remuneração.

O reforço monetário foi importante, mas não terá sido a motivação principal para iniciar este projeto, mas a possibilidade de escolher os elementos do grupo com quem se trabalha e de ter as condições de trabalho exigidas para o exercício digno da MGF. O que mudamos foi a forma de organização e, para isso, foi preciso mudar mentalidades quer ao nível da equipa quer sobretudo ao nível das estruturas de administração da saúde, completamente impreparadas para conceber e aceitar esta nova forma de organizar cuidados de saúde. ${ }^{7}$

Após o início de funções, em finais de 1999, seguiu-se uma fase de grande trabalho de organização interna e de atividade clínica. Nos primeiros meses de atividade recebemos, nas USF, centenas ou milhares de cidadãos que nunca tinham tido ou já não tinham médico de família há muito tempo. Eram também pessoas com hábitos de utilização dos serviços muito ligados ao que lhes era oferecido no passado. Entre outras particularidades, não havia hábitos de marcar consultas, de respeitar horários, de fazer atividades preventivas ou de obter renovação de medicação sem estar presente. Foram meses ou mesmo anos de desenvolvimento de uma nova forma de estar que necessitaram de grande esforço dos profissionais.

Lentamente conseguimos desenvolver o nosso projeto, ao mesmo tempo que íamos colaborando com as outras unidades em RRE para desenvolver modelos de avaliação, tarefa muito dificultada pela ausência de apoio do aparelho do Ministério da Saúde (MS) e pelas insuficiências do sistema de informação. 
Importa recordar que as USF em RRE iniciaram funções sem que existisse ainda um sistema de informação clínico eletrónico. As inscrições dos cidadãos e o registo de consultas e atos médicos era efetuado através do SINUS, ${ }^{8}$ mas durante muito tempo os registos clínicos continuaram a ser manuais e em papel. Esta situação acarretava enormes limitações na capacidade de produção e processamento de dados para avaliação de desempenho, já para não falar na própria organização e gestão da atividade clínica. Dada a inexistência de um programa informático de registo clínico, para conseguir produzir dados para avaliação tínhamos de estudar os processos clínicos por amostragem ou de utilizar outras metodologias de investigação. ${ }^{9}$

Como se referiu num trabalho publicado em 2003, alguns grupos depararam-se ainda, desde o início, com problemas estruturais graves relacionados com obras, mobiliário, infraestruturas, etc. Estes problemas afastaram os profissionais do seu verdadeiro trabalho, que é a prestação de cuidados de saúde, e só posteriormente foi possível reorientar a atenção para os problemas clínicos. As remunerações não eram cumpridas atempadamente, inicialmente por problemas de aplicação do programa de cálculo, sanados ao fim de oito meses de trabalho, período em que os médicos receberam um ordenado inferior ao que receberiam fora do RRE.

E assim o modelo RRE foi-se mantendo, com muita persistência e resiliência dos profissionais e muito desinteresse por parte do aparelho do Ministério da Saúde. Os anos seguintes foram de grandes dificuldades e angústias. A proposta dos centros de saúde de terceira geração nunca viu a luz do dia, pois as mudanças ocorridas no seio do próprio Governo e a chegada de Manuela Arcanjo ao ministério levaram ao congelamento da reforma; a subsequente substituição da ministra por Correia de Campos (versão 1) manteve ainda o bloqueio dos projetos de reforma e inovação. ${ }^{10} \mathrm{Com}$ o ministro Luís Filipe Pereira chegou, em 2002, a contrarreforma e as tentativas de destruição da estrutura dos CSP, felizmente sem grande sucesso. Só em 2005, com Correia de Campos (versão 2), foi possível relançar a reforma.

Seguiram-se os anos da Missão para os CSP, de grande empenho e fervor no lançamento da USF e da explosão de candidaturas e abertura de novas unidades. ${ }^{11-12} \mathrm{~A}$ satisfação que tivemos com o novo fôlego para a reforma e a esperança num modelo organizacional apoiado pelo programa do Governo e pelas estruturas do Ministério da Saúde cedo veio a dar lugar a alguma desilusão. A experiência dos RRE foi quase completamente esquecida, subalternizada, quase como se nunca tivesse existido. As verdadeiras USF eram as nascidas após 2005. O nosso contributo para os primeiros passos da reforma e para a criação dos primeiros textos de apoio ao desenvolvimento do modelo organizacional foi completamente desvalorizado. Fomos inclusive admoestados por persistir em usar a designação USF antes de nos voltarmos a candidatar ao abrigo da nova legislação.

A fase seguinte foi difícil e exigiu da nossa parte um enorme esforço de integração na nova forma de pensar, muito administrativa, muito centrada nas questões processuais e organizacionais, com menos enfoque na clínica, na relação com os cidadãos, nas atividades de formação e de investigação. Simultaneamente, algumas das unidades, que tinham nascido no âmbito do RRE, foram-se renovando com a saída de vários profissionais e a substituição por novos elementos. Esta renovação acarretou igualmente a necessidade de muitos ajustes. Os novos elementos não tinham participado no processo de construção das USF/RRE e traziam ideias novas mais adaptadas ao que se pensava e praticava noutros locais. Era urgente mudar a nossa própria forma de estar, uma verdadeira reforma do pensamento, ${ }^{13}$ o que encontrou naturais resistências, sobretudo da parte de alguns dos fundadores ainda no ativo.

Em 2007, num editorial da ainda RPCG, escrevi o seguinte: "A mudança depara ainda com [a] resistência de muitos colegas, os que têm algo a perder (muitas chefias, profissionais desmotivados, com interesses instalados), os que não se revêm na reforma (acham que não é necessário um novo modelo) ou ainda os grupos que se auto-excluíram por discordar dos objectivos e percurso da reforma". ${ }^{10: 121}$ Estou convencido que, passados doze anos, estas reflexões ainda têm alguma atualidade. A reforma estagnou muito nos últimos anos. A atividade das USF e do aparelho do MS cristalizou-se em torno de muitos detalhes organizacionais, intermináveis auditorias, focalizando-se sobretudo na avaliação de desempenho organizacional através de indicadores de processo de interesse duvidoso, com pouca diversificação e inovação nos indicadores clínicos que permitam demonstrar boas práticas e objetivem ganhos em 
saúde. Uma das facetas menos agradáveis do atual modelo é a rigidez organizacional: um figurino único aplicável em qualquer contexto ou geografia e que está a deixar de fora muitos cidadãos e profissionais. ${ }^{14} \mathrm{E}$ isto é uma fragilidade do modelo.

Apesar da evolução muito positiva do modelo de avaliação dos últimos anos, continua a existir fraca evidência científica de alguns indicadores, utilidade muito discutível de outros, bem como a dificuldade em medir ganhos em saúde, o que pode originar excessos da medicina, nomeadamente medicalização, consumismo e iatrogenia. O ideal seria que o pagamento por desempenho fosse baseado na medição de indicadores que representem ganhos em saúde para as pessoas, respeitando igualmente os princípios e a prática da MGF. ${ }^{15}$

Adicionalmente, não existe espaço para que os profissionais se possam dedicar a outras tarefas para além da USF. Apesar de teoricamente encorajadas pela retórica expressa nos diplomas orientadores, as atividades de investigação, o ensino universitário, a participação em comissões ou grupos de trabalho no âmbito do ministério da saúde, tanto a nível local como central, é prejudicada pela pressão assistencial. São numerosos os exemplos de colegas que são forçados a sacrificar a possibilidade de se dedicarem a outras atividades de interesse profissional ou de desenvolvimento pessoal ao serem confrontados com a pressão dos pares, constantemente preocupados com os constrangimentos da produção de indicadores ou da certificação. $\mathrm{O}$ trabalho a tempo parcial, previsto na lei, é desencorajado e são poucos os casos em que foi autorizado.

O meu sentimento é que a reforma dos CSP se afastou muito do que eu e o conjunto de pioneiros idealizamos em 1998-99. É possível, mesmo muito provável, que tenha evoluído para um modelo melhor, mais sustentado, mais adequado às necessidades da população, mais generalizável e, sobretudo, mais fácil de avaliar. Não digo o contrário. Mas a realidade é que nós, os pioneiros, aspirávamos a algo de diferente e não nos foi fácil a integração.

Apesar de tudo, olhando para o já longo percurso de 20 anos de RRE, não posso deixar de sentir um sentimento de grande orgulho e satisfação por tudo o que fizemos. Agora mais próximo do fim de carreira, avaliando retrospetivamente o nosso contributo para a saúde da nossa população, julgo poder afirmar que o nosso principal legado é a nossa relação com os cidadãos, a forma como as equipas se relacionam entre si, a exigência e o rigor da qualidade da prática clínica, a procura da inovação e a atividade constante de ensino, formação e investigação, da qual nunca desistimos e que tem permitido disseminar por esse País fora e até para além fronteiras um número já considerável de médicos de família formados nas USF, para quem não terá sido indiferente o tempo que passaram connosco.

Em conclusão, em abono da verdade, pode-se afirmar que, apesar de existirem mudanças substanciais nos últimos anos na vontade política de relançar a reforma e no que se refere à construção e aplicação do sistema de avaliação de desempenho, a minha perceção é que não existe suficiente reflexão e debate nem consenso alargado sobre o modelo de CSP em Portugal e sobre a direção da evolução futura do sistema. Apesar das enormes qualidades, o modelo USF tem muitos pontos fracos e numerosas insuficiências, sendo urgente aprofundar a reflexão sobre como e para onde evoluir para a sua modernização e atualização. ${ }^{16}$

Na realidade, já passaram mais de 20 anos desde que o modelo foi pensado...

Nota aos leitores: $\mathrm{O}$ autor publicou recentemente um texto de estrutura e conteúdo muito semelhantes aos do presente texto numa obra de celebração dos 20 anos da USF Horizonte, ainda no prelo. Dada a natureza algo mais intimista do referido texto, muito relacionada com aspetos específicos da história da USF Horizonte, optou-se por reduzir, rever e adaptar esse texto ao formato de um editorial para a RPMGF com o objetivo de permitir alargar a um público mais vasto o conjunto de reflexões contidas nesse texto.

\section{REFERÊNCIAS}

1. Conceição C, Fronteira I, Hipólito F, Van Lerberghe W, Ferrinho P. Os grupos Alfa e a adesão ao regime remuneratório experimental [Alpha groupsand the adhesion to the experimental remuneratory system]. Rev Port Clin Geral. 2005;21(1):45-59. Portuguese

2. Decreto-Lei n. ${ }^{\circ} 117 / 98$, de 5 de maio. Diário da República. I Série$A(103)$.

3. Associação Portuguesa dos Médicos de Clínica Geral. Um futuro para a medicina de família em Portugal. Lisboa: APMCG; 1991

4. Rodrigues A, Biscaia JL. Pensar uma unidade de medicina de família. Rev Port Clin Geral. 1991;8(8):248-53.

5. Correia-de-Sousa J, Campos L, Miranda M, Lima MA, Costa MG, Ornelas $M M$, et al. Evolução do conceito de centro de saúde no âmbito do novo 
estatuto do S.N.S. e a criação do nível local de administração de saúde [Evolution of the concept of health center in the contexto of the new National Health Service Act and the development of health administration at the local level]. Acta Med Port. 1994;7(6):385-90. Portuguese

6. Associação Portuguesa dos Médicos de Clínica Geral. Declaração da Madeira. Lisboa: APMCG; 1998.

7. Correia-de-Sousa J, Ribas MJ, Silva ML. O regime remuneratório experimental (RRE): uma pedrada no charco. In: Pinto AS, editor. Experiência de gestão: $2^{\circ}$ fórum de Economia da Saúde. Porto: Faculdade de Medicina da Universidade do Porto; 2003. p. 141-67.

8. Faculdade de Medicina da Universidade do Porto. AprendIS: sistema de informação para unidades de saúde [homepage]. 2016 [cited 2019 Sep 14]. Available from: http://aprendis.gim.med.up.pt/index.php/SINUS 14/09/2019

9. Jelley D, Biscaia A. Medicina geral e familiar portuguesa - Os sucessos e os desafios: uma visão de fora [Portuguese family medicine - Successes and challenges: a view from outside]. Rev Port Clin Geral. 2004;20(2):173-89. Portuguese

10. Correia-de-Sousa J. A raposa e as uvas: um olhar sobre a reforma dos cuidados de saúde primários [The fox and the grapes: a look at primary health care reform]. Rev Port Clin Geral. 2007;23(2):117-22. Portuguese

11. Pisco L. Reforma da atenção primária em Portugal em duplo movimento: unidades assistenciais autónomas de saúde familiar e gestão em agrupamentos de centros de saúde [Primary healthcare reform in
Portugal on two fronts: autonomous family healthcare units and management of groupings of health centers]. Cien Saude Colet. 2011;16 (6):2841-52. Portuguese

12. Rocha Paulo de Medeiros, Sá Armando Brito de. Reforma da Saúde Familiar em Portugal: avaliação da implantação [Family health reform in Portugal: analysis of its implementation]. Cien Saude Colet. 2011;16(6): 2853-63. Portuguese

13. Biscaia AR. A reforma dos cuidados de saúde primários e a reforma do pensamento [The reform of primary care and thought reform]. Rev Port Clin Geral. 2006;22(1):67-79. Portuguese

14. Broeiro-Gonçalves P. Utentes sem equipa de saúde: uma prioridade e uma responsabilidade social. Rev Port Med Geral Fam. 2019;35(3):172-4.

15. Melo M, Correia-de-Sousa J. Os indicadores de desempenho contratualizados com as USF: um ponto da situação no actual momento da reforma [Performance indicators contracted with family health units: a progress report on the current moment of primary health care reform in Portugal]. Rev Port Clin Geral. 2011;27(1):28-34. Portuguese

16. Santos AM, Giovanella L, Botelho H, Correia-de-Sousa J. Desafios organizacionais para fortalecimento da atenção primária à saúde em Portugal [Organizational challenges in strengthening primary health care in Portugal]. Rev Bras Educ Med. 2015;39(3):359-69. Portuguese

\section{ENDEREÇO PARA CORRESPONDÊNCIA}

E-mail: jaimecsousa@gmail.com

https://orcid.org/0000-0001-6459-7908 